\title{
Effect of vitamin A deficiency on the immune response to epizootic diarrhoea of infant mice (EDIM) rotavirus infection in mice
}

\author{
BY FARUK AHMED ${ }^{1}$, DAVID B. JONES ${ }^{2}$ AND ALAN A. JACKSON ${ }^{1, *}$ \\ ${ }^{1}$ Department of Human Nutrition and ${ }^{2}$ Department of Pathology, University of Southampton, \\ Bassett Crescent East, Southampton SO9 $3 T U$
}

(Received 29 June 1990 - Accepted 2 November 1990)

\begin{abstract}
The effect of vitamin A deficiency on the immune response to epizootic diarrhoea of infant mice (EDIM) rotavirus was studied in mice. The virus was given by oral dosing or by intraperitoneal injection. For oral challenge, weanling mice were fed on either a control or vitamin A-deficient diet ad lib. or pair-fed the control diet to the intake of the vitamin A-deficient group. A fourth group was fed on the vitamin Adeficient diet ad lib. for 10 weeks and then refed the control diet for 2 weeks. On day 77, mice were each given $30 \mu \mathrm{l}$ EDIM rotavirus orally and the animals were killed and examined 1 week later. The delayedtype hypersensitivity (DTH) response to picryl chloride was measured as an index of cell-mediated immunity. For intraperitoneal challenge, weanling mice were fed on either the control diet or the vitamin A-deficient diet ad lib. or pair-fed the control diet to the intake of the vitamin A-deficient group. On day 77 , mice were each injected intraperitoneally with $30 \mu \mathrm{l}$ EDIM rotavirus and 1 week later antibody production was measured. In both experiments the body-weight, liver and serum vitamin $A$ levels of the vitamin A-deficient group were significantly lower than the control or pair-fed groups. Following oral dosing the serum antibody levels specific to rotavirus were statistically significantly lower in vitamin Adeficient animals than the control or pair-fed groups. Vitamin A-deficient mice also showed an impaired DTH response compared with the control and pair-fed animals. Animals refed vitamin A for a short period showed a partial restoration of the antibody response. Following intraperitoneal challenge no statistically significant changes were observed in the serum antibody levels between any of the dietary groups. It is concluded that vitamin A deficiency impaired antibody production when rotavirus was given orally. Vitamin A deficiency also impaired cell-mediated immunity.
\end{abstract}

Vitamin A: Antibody: Immune response: Mouse

Vitamin A deficiency is one of the most common dietary deficiencies in the world (Roels, 1970) and is especially common in developing countries (Pirie, 1983). A number of reports have shown an association between vitamin A deficiency and an increased susceptibility to infectious diseases (Bang \& Foard, 1971; Krishnan et al. 1976; Nauss et al. 1985). We have also shown that vitamin $\mathrm{A}$-deficient mice are more susceptible to rotavirus infection than normal counterparts. We have found a breakdown in the non-specific barrier to infection as revealed by histopathological changes in the gut mucosa and a decreased number of goblet cells in the villi of the small intestine, implying impaired mucus secretion in both infected and non-infected vitamin A-deficient animals (Ahmed et al. 1990). To evaluate specific immunity to rotavirus, it is necessary to investigate antibody levels.

The effect of vitamin A deficiency on antibody production has been investigated by a

\footnotetext{
* For reprints.
} 
number of groups. Many of these studies have claimed impaired antibody production in the vitamin A-deficient subjects (Ludovici \& Axelrod, 1951; Pruzansky \& Axelrod, 1955; Panda \& Combs, 1963; Chandra \& Au, 1981). Others have found no significant changes in antibody production in vitamin A deficiency (Krishnan et al. 1974; Davis \& Sell, 1983). Taken together, these findings suggest that antibody production in response to different antigens in vitamin A deficiency varies depending on the experimental system employed.

Most investigations have shown impaired antibody production in vitamin A-deficient animals when antigen is injected either by the intraperitoneal or the intramuscular route. Few studies have investigated the effect of vitamin A deficiency on antibody production following oral presentation of antigen (Sirisinha et al. 1980). The present study was designed to compare the effect of vitamin A deficiency on antibody production following either oral dosing or intraperitoneal immunization with live rotavirus. Live rotavirus when given orally acts both as an antigen and as an infective agent, whereas following intraperitoneal challenge it presents only an antigenic stimulus. The studies were carried out at the earliest time at which definite vitamin A deficiency could be established in the mouse. On the basis of body-weight, hepatic vitamin A content and plasma vitamin A concentration, biochemical and clinical vitamin A deficiency was apparent after 63-70 d on the deficient diet. The results of the present study show an impairment of antibody production in vitamin $\mathrm{A}$ deficiency following oral challenge.

\section{MATERIALS AND METHODS}

\section{Oral challenge}

Animals and diet. Male Porton mice from a locally-bred colony were received at weaning (20-21 d old). They were housed in groups of two or three in plastic cages at a room temperature of $20 \pm 2^{\circ}, 50 \%$ humidity and a $12 \mathrm{~h}$ lighting schedule each day. The animals were fed one of four diets formulated for the purpose of the present study. A control group was allowed $a d l i b$. access to a diet which provided a balanced nutrient intake. The deficient group was allowed $a d$ lib. access to a diet which was deficient in vitamin A. A third group was allowed limited access to the control diet, being pair-fed to the intake of the deficient group on the previous day. A fourth group was fed on the vitamin A-deficient diet for 10 weeks then refed the control diet ad lib. for 2 weeks (vitamin A-refed group).

The deficient diet, a vitamin A-free basal diet, supplied all other nutrients to the recommended level for the mouse (American Institute of Nutrition, 1977) and has been described elsewhere (Ahmed et al. 1990). The control and pair-fed diets were formulated in a similar way to the deficient diet, but contained added vitamin A (retinyl palmitate, as stabilized powder) at $1.2 \mathrm{mg} / \mathrm{kg}$ diet. Food consumption was measured daily and bodyweight was measured at weekly intervals.

Oral dosing. On day 77 of receiving the experimental diet, mice from each dietary group were subdivided into infected and non-infected groups. Viral inoculum was titrated to give a value for the dose which induced diarrhoea in $50 \%$ of the infected mice $\left(\right.$ ID $\left._{50}\right)$ and the infected group was given $30 \mu \mathrm{l}$ epizootic diarrhoea of infant mice (EDIM) rotavirus (ID $_{50}$ estimated to contain $10^{4.5}$ virus particles) by oral dosing. This dose was sufficient to cause diarrhoea in infant mice fed on a balanced diet (Starkey et al. 1986).

Delayed hypersensitivity test. On day 78 ( $1 \mathrm{~d}$ after oral dosing with rotavirus) the animals in the infected group were sensitized with picryl chloride $(50 \mathrm{~g} / 1)$ in acetone-alcohol $(1: 9$, $\mathrm{v} / \mathrm{v})$ applied on the shaved abdomen $(150 \mu \mathrm{l})$ and to each of the four foot pads $(50 \mu \mathrm{l})$. Noninfected animals received the same amount of acetone and alcohol solution on the shaved abdomen and the four foot pads. At $24 \mathrm{~h}$ before killing the ear thickness of all the animals was measured with a micrometer. This was followed by a challenge with picryl chloride 
solution $(10 \mathrm{~g} / \mathrm{l})$ in acetone-olive oil $(1: 9, \mathrm{v} / \mathrm{v})$ on both ears. On day 84,1 week post dosing, the ear swelling of all the animals was measured.

On day 84 , animals were lightly anaesthetized by inhalation of Metophan for the collection of blood by heart puncture before death. The blood samples were centrifuged at $2000 \mathrm{~g}$ for $5 \mathrm{~min}$, the serum separated and stored at $-20^{\circ}$. The weighed liver was stored at $-20^{\circ}$ for vitamin A estimation.

\section{Intraperitoneal challenge}

Three groups of animals were fed on either vitamin A-deficient or control diets or pair-fed to the intake of the vitamin A-deficient group as described for the oral challenge. On day 77 of receiving the experimental diet each of the dietary groups was subdivided into immunized and non-immunized groups. The immunized animals were each given $30 \mu \mathrm{l}$ EDIM rotavirus intraperitoneally. On day 84 , blood samples were collected as described for the oral challenge.

\section{Analytical procedures}

Vitamin A in liver was measured by the method of Bayfield (1975), with modifications. In brief, the liver was homogenized in ethanol, and the vitamin A extracted with hexane. The top hexane layer was collected and evaporated. The vitamin A extracted was redissolved in chloroform and quantified spectrophotometrically, using trichloroacetic acid at $620 \mathrm{~nm}$.

Vitamin $\mathrm{A}$ in serum was measured by the high-performance liquid chromatographic method of Bieri et al. (1979) with slight modifications using a Kratos solvent delivery system (Spectroflow 400), a programmable absorbance detector (Spectroflow 783), Spectra Physics autosampler (SP 8780) and Spectra Physics programmable injector (SP 4290). The vitamin $\mathrm{A}$ was extracted from serum with ethanol and hexane. The top hexane layer was collected, dried under a stream of nitrogen gas and redissolved in methanol. Vitamin A solution was injected into a reverse-phase Spherisorb ODS2 column $(250 \mathrm{~mm} \times 4.5 \mathrm{~mm})$. Vitamin A was separated with a methanol-water $(97 \cdot 5: 2 \cdot 5, \mathrm{v} / \mathrm{v})$ solvent. Absorbance at $325 \mathrm{~nm}$ was used to measure retinol. Retinyl acetate was used as an internal standard.

Total serum antibody specific to rotavirus was measured using a cell lysate enzymelinked immunosorbent assay (ELISA) technique. A $100 \mu 1$ portion of an optimum dilution of simian rotavirus (SA11) in protein-coupling buffer $(1.59 \mathrm{~g}$ sodium carbonate and $2.93 \mathrm{~g}$ sodium bicarbonate in 11 solution, $\mathrm{pH} 9.4$ ) was added to each well of a ninety-six well polyvinyl microtitre plate and incubated at $37^{\circ}$ for $1 \mathrm{~h}$. Following incubation at $4^{\circ}$ overnight, the plates were washed once with phosphate-buffered saline $(9 \mathrm{~g}$ sodium chloride/1) containing Tween 20 (PBS-Tween; $5 \mathrm{ml} / \mathrm{l}$ ) and incubated at $37^{\circ}$ for $1 \mathrm{~h}$ with $100 \mu \mathrm{l}$ bovine serum albumin $(10 \mathrm{~g} / \mathrm{l})$ in phosphate-buffered saline (PBS-BSA) solution/well, and washed twice. Monoclonal mouse anti-rotavirus antibody (prepared as $1: 125$ dilution in PBS-BSA) was used as a standard and was serially diluted in the plate with PBS. The serum samples were diluted appropriately and incubated for $90 \mathrm{~min}$ at room temperature, and washed with PBS-Tween solution five times. Then $100 \mu \mathrm{l}$ rabbit antimouse Ig peroxidase (EC 1.11.1.7)-conjugate (at appropriate dilution in PBS-BSA) was added to each well and incubated for a further $90 \mathrm{~min}$. After five further washes with PBS-Tween, $100 \mu \mathrm{l}$ substrate $(20 \mathrm{mg} o$-phenylene diamine in $100 \mathrm{ml}$ phosphate-citrate buffer containing $40 \mu 1$ hydrogen peroxide, $300 \mathrm{ml} / \mathrm{l}$ ) was added to each well and the plates incubated for $30 \mathrm{~min}$. The reaction was stopped by adding $50 \mu 12.5 \mathrm{M}$-sulphuric acid/well. Optical density (OD) was measured in a micro ELISA reader (model MR 580) at $490 \mathrm{~nm}$. The units of anti-rotavirus activity were defined for the standard serum as a dilution of serum $\mathrm{X}\left(1 \times 10^{6}\right)$. For each serum under test a doubling dilution curve was prepared by 
assay using ELISA. The units of antibody present were then obtained by extrapolating from the standard curve using the lowest dilution of test serum for which the OD value lay on the linear portion of the standard curve.

\section{Statistical analysis}

Results are expressed as means with their standard errors of the mean. Differences between different dietary groups and between infected and non-infected animals in each of the dietary groups were evaluated by using Student's $t$ test for the independent means. A twoway analysis of variance (ANOVA) for independent means was also carried out to test the interaction term. The results of the antibody studies were analysed using the Wilcoxon rank sum test (Goldstone, 1983).

\section{RESULTS}

Oral dosing

Body-weight. In the non-infected animals, the final body-weights of the vitamin A-deficient and vitamin A-refed animals were significantly lower than those of the control $(P<0 \cdot 01)$ and pair-fed animals $(P<0.05$, Fig. 1$)$. The infected animals in all dietary groups showed a small (but not statistically significant) fall in the body-weight after rotavirus dosing and picryl chloride challenge. In the infected groups, the body-weights of the vitamin Adeficient and vitamin A-refed animals were significantly lower than those of the control and pair-fed animals $(P<0.05)$. In both the non-infected and infected groups, there was no significant difference in body-weights between control and pair-fed animals or between vitamin A-deficient and vitamin A-refed animals.

Using two-way ANOVA, there was no significant interaction between diet and rotavirus infection on the final body-weights (Fig. 1).

Vitamin A levels. In both the non-infected and infected animals, the liver vitamin A level of the vitamin A-deficient animals was significantly lower than that of the corresponding control, pair-fed and vitamin A-refed animals $(P<0.001$, Table 1$)$. The vitamin A-refed group showed an increase in liver vitamin A level but this was still significantly less than that of the control and pair-fed animals $(P<0.01)$. Following infection, the liver vitamin A levels of each dietary group were not significantly different from those of the non-infected counterpart. There was no significant interaction between diet and infection on liver vitamin A, when two-way ANOVA was performed.

In both the non-infected and infected groups, using the $t$ test, the serum vitamin A levels of the vitamin A-deficient animals were significantly lower than those of the corresponding control, pair-fed and vitamin A-refed groups $(P<0.001$, Table 1$)$. The serum vitamin A levels of the vitamin A-refed group were significantly lower than those of the control group ( $P<0.05$ for non-infected groups, $P<0.001$ for the infected group). The serum vitamin A levels of the vitamin A-refed animals tended to be less than those of the pair-fed animals in both the non-infected and the infected groups, but only in the infected groups did the difference reach statistical significance $(P<0.001)$. Following infection, the serum vitamin A level of each of the dietary groups was significantly reduced when compared with the non-infected counterpart $(P<0 \cdot 001)$.

With two-way ANOVA, no significant interaction was demonstrated between diet and infection for serum vitamin A (Table 1).

Serum antibody levels. The total serum antibody levels, specific to rotavirus, are shown in Table 2. The rotavirus antibody levels from the non-infected animals are shown as the mean of all groups. The serum samples from each group were pooled and the antibody levels measured; this level represents the background rotavirus antibody titre. These mice 

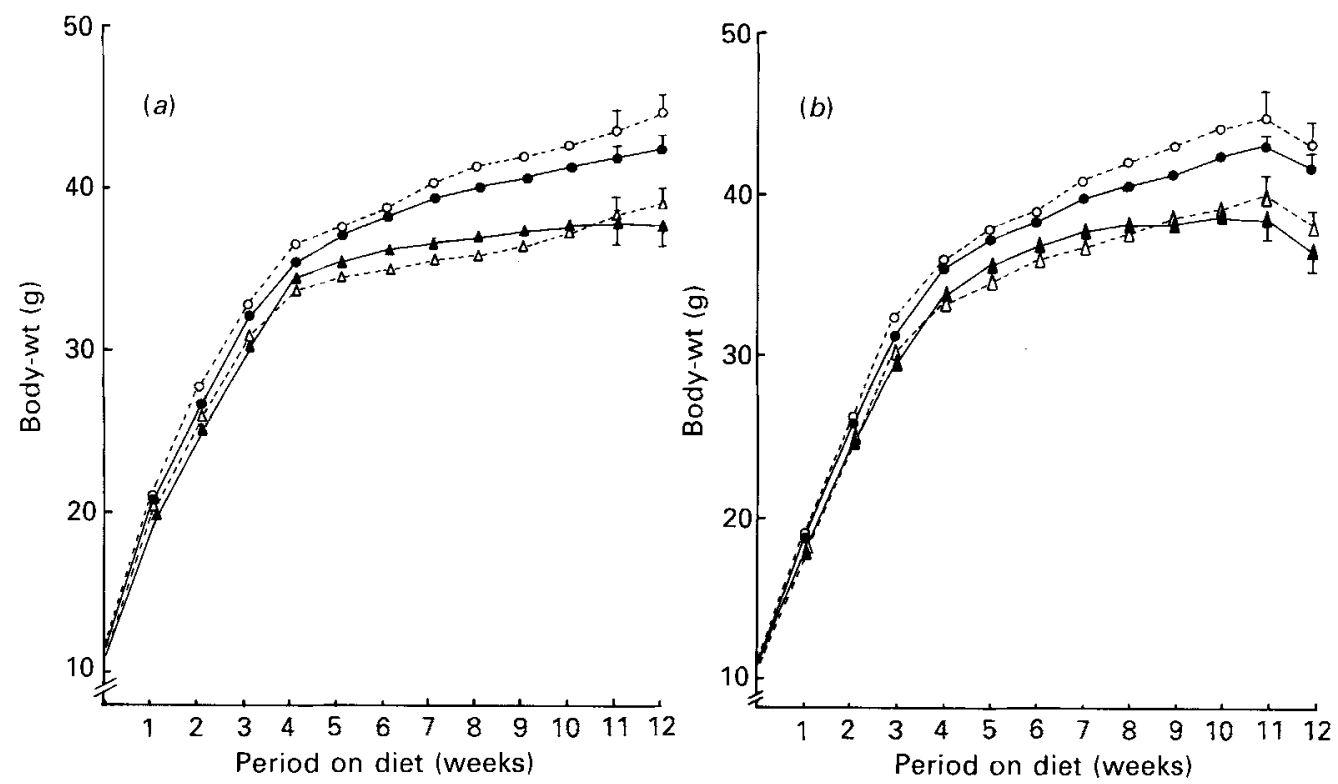

Fig. I. Body-weight gains of groups of mice given one of the four experimental diets for 12 weeks and an oral dose of rotavirus at week 11, and killed 1 week later. $(a)$ Non-infected and $(b)$ orally infected groups given. (O) Control diet, ( $(\mathbf{)})$ pair-fed at intakes of vitamin A-deficient group, (A) vitamin A-deficient diet, $(\triangle)$ vitamin $\mathbf{A}$-refed Points represent the means of five animals and at 11 and 12 weeks, points are means with their standard errors. For details of diets and procedures, see p. 476.

Table 1. Vitamin A contents of the liver and serum of groups of mice given one of the four experimental diets for 12 weeks and an oral dose of rotavirus at week 11

(Mean values with their standard errors for five samples per group)

\begin{tabular}{|c|c|c|c|c|c|c|c|c|}
\hline \multirow{3}{*}{$\begin{array}{l}\text { Treatment } \$ \ldots \\
\text { Dietary group } \$\end{array}$} & \multicolumn{4}{|c|}{ Liver ( $\mu \mathrm{g} /$ liver $)$} & \multicolumn{4}{|c|}{ Serum $(\mu \mathrm{g} / \mathrm{l})$} \\
\hline & \multicolumn{2}{|c|}{ Non-infected } & \multicolumn{2}{|c|}{ Infected } & \multicolumn{2}{|c|}{ Non-infected } & \multicolumn{2}{|c|}{ Infected } \\
\hline & Mean & SEM & Mean & SEM & Mean & SEM & Mean & SEM \\
\hline Control & $236 \cdot 0+5+$ & 8.5 & $232 \cdot 0+1+5$ & $8 \cdot 7$ & $472 \dagger$ & 13 & $191+t+t+t$ & 11 \\
\hline Pair-fed & $227 \cdot 0+t+$ & $6 \cdot 8$ & $216.0+1+$ & $9 \cdot 8$ & 436 & 43 & $177+t++t+$ & 11 \\
\hline Vitamin A-deficient & $0.4 * * *$ & $0 \cdot 1$ & $0.5 * * *$ & $0 \cdot 1$ & $51 * * *$ & 4 & $20 * * *++4$ & 1 \\
\hline Vitamin A-refed & $15 \cdot 6$ & 0.7 & $13 \cdot 3$ & 0.5 & 346 & 36 & $99+4 \div$ & 5 \\
\hline
\end{tabular}

Mean values were significantly different from those of any of the other dietary groups $(t$ test $): * * * P<0 \cdot 001$. Mean values were significantly different from those of vitamin A-refed group ( $t$ test) : $\uparrow P<0.05, \dagger \dagger \dagger P<0.001$. Mean values were significantly different from those of non-infected animals for serum vitamin A $(t$ test $)$ : $+4 P<0.001$.

$\S$ For details, see p. 476.

were conventional animals and the low levels of rotavirus antibody in the circulation imply that they had previously been exposed to rotavirus. After rotavirus challenge, there was a substantial increase in serum rotavirus antibody levels in all dietary groups when compared with non-infected controls. In the infected group, the antibody level of vitamin A-deficient animals was significantly lower than those of the control and pair-fed groups 
Table 2. Total serum antibody levels specific to rotavirus for groups of mice given one of the four experimental diets for 12 weeks and an oral dose of rotavirus at week 11

(Results are expressed as the units of anti-rotavirus activity extrapolated from the standard curve of the standard serum. For the non-infected group, results are the mean of pooled serum of five samples in each dietary group and, for the infected group, mean values with their standard errors are for five samples in each dietary group)

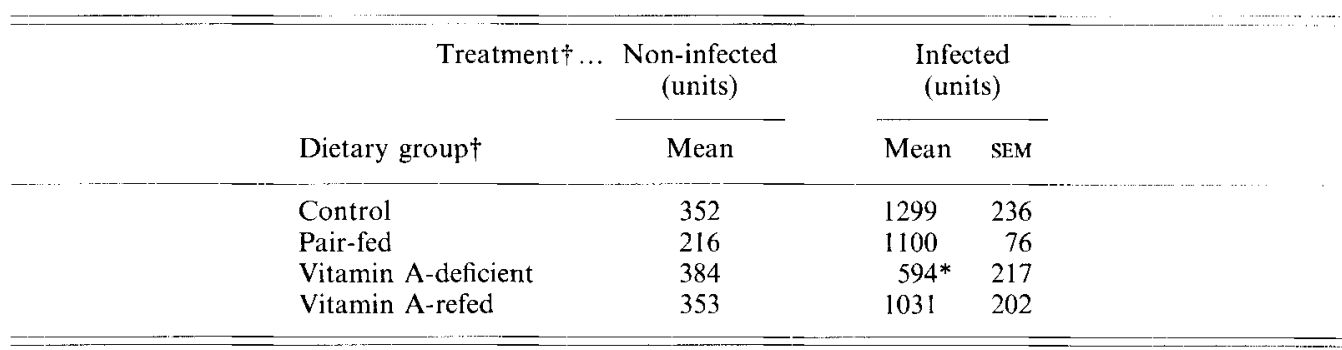

Mean values were significantly different from those for control and pair-fed groups (Wilcoxon test): ${ }^{*} P<0.05$. $\uparrow$ For details, see p. 476.

$(P<0 \cdot 05)$. Although the vitamin A-refed group had a higher mean antibody titre than the vitamin A-deficient group this level was intermediate between those of the control and vitamin A-deficient groups. The differences between vitamin A-refed and vitamin Adeficient animals or between vitamin A-refed and control animals were not statistically significant.

Delayed-type hypersensitivity response. Cutaneous challenge with picryl chloride was used to assess the delayed-type hypersensitivity response and the results were expressed as the percentage increase in ear thickness for each dietary group (Fig. 2). In animals which had not received oral dosing (non-infected group) and had not been sensitized with picryl chloride, there was no significant increase in ear thickness in any of the dietary groups following challenge with picryl chloride. In animals which had received oral dosing with rotavirus (infected group) and had been sensitized with picryl chloride, there was a highly significant increase in ear thickness following challenge with picryl chloride for all the groups $(P<0.001)$. The increase in ear thickness was similar for the control and pair-fed groups on the one hand and for the vitamin A-deficient and vitamin A-refed groups on the other; in each case the difference between the two groups was statistically significant $(P<0.05)$.

\section{Intraperitoneal challenge}

Body-weight. In both non-infected and infected animals, the final body-weights of the vitamin A-deficient animals were significantly lower than those of the control $(P<0.01)$ and pair-fed arimals $(P<0 \cdot(i)$. There was no significant difference in body-weight between the control and pair-fed roups. Using two-way ANOVA, there was no significant interaction between diet and imn inization on the body-weights.

Vitamin A levels. In both non-imı. unized and immunized animals, the total liver vitamin $A$ contents and the serum vitamin A levels of th $z$ vitamin A-deficient animals were significantly lower than those of the corresponding co itrol and pair-fed animals $(P<0.001$, Table 3). No significant difference was observed between control and pair-fed groups. Immunization did not have any significant effect on the liver vitamin A or the serum vitamin A levels. Using two-way ANOVA, there was no significant interaction between diet and immunization for either the liver or serum vitamin $\mathrm{A}$.

Serum antibody levels. The total serum antibody levels specific for rotavirus in both immunized and non-immunized animals are shown in Table 4 . In the case of non- 


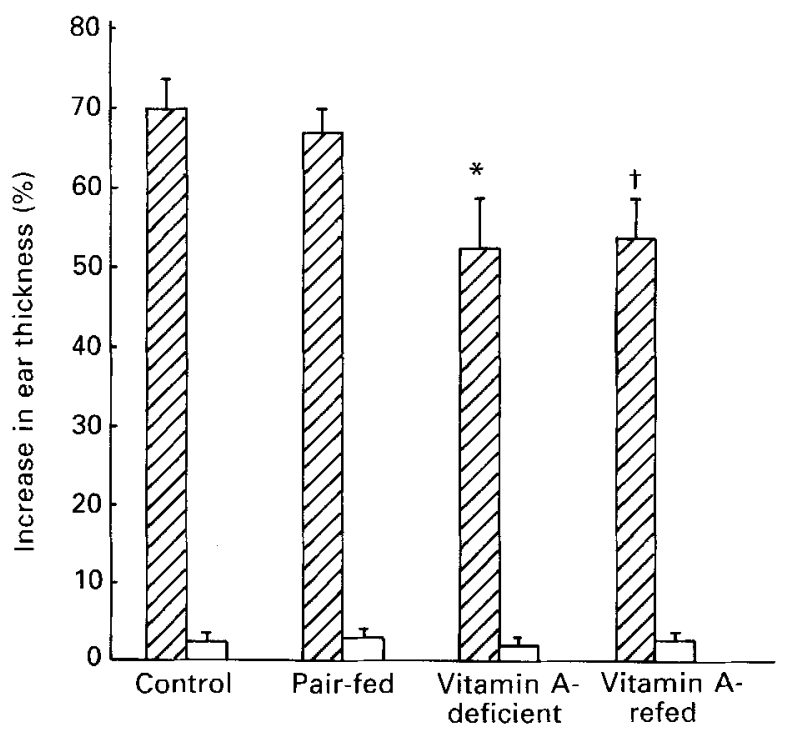

Dietary treatment groups

Fig. 2. Delayed-type hypersensitivity responses to the skin-contact allergen picryl chloride in groups of mice given one of four experimental diets for $84 \mathrm{~d}$ (12 weeks). On day 77 , animals from each infected group were sensitized with picryl chloride and animals from the non-infected group sensitized with vehicle only. On day 83, all animals were challenged with picryl chloride and $24 \mathrm{~h}$ later (on day 84) increases in ear thickness were measured. ( $\square$ ), Noninfected; (娄), infected. Values are means of five animals with their standard errors represented by vertical bars. Mean values were significantly different from those of the control and pair-fed groups: $* P<0 \cdot 05$. Mean values were significantly different from those of the control group: $\uparrow P<0.05$.

Table 3. Vitamin A contents of the liver and serum of groups of mice given one of the three experimental diets for 12 weeks and an intraperitoneal injection of rotavirus at week 11

(Mean values with their standard errors for five samples per group)

\begin{tabular}{|c|c|c|c|c|c|c|c|c|}
\hline \multirow{3}{*}{$\begin{array}{l}\text { Treatment } \dagger \ldots \\
\text { Dietary group }{ }^{\dagger}\end{array}$} & \multicolumn{4}{|c|}{ Liver $(\mu \mathrm{g} /$ liver $)$} & \multicolumn{4}{|c|}{ Serum $(\mu \mathrm{g} / 1)$} \\
\hline & \multicolumn{2}{|c|}{ Non-immunized } & \multicolumn{2}{|c|}{ Immunized } & \multicolumn{2}{|c|}{ Non-immunized } & \multicolumn{2}{|c|}{ Immunized } \\
\hline & Mean & SEM & Mean & SEM & Mean & SEM & Mean & SEM \\
\hline Control & $219 \cdot 0$ & $7 \cdot 6$ & $230 \cdot 0$ & $8 \cdot 2$ & 430 & 38 & 440 & 30 \\
\hline Pair-fed & $208 \cdot 0$ & $10 \cdot 0$ & $206 \cdot 0$ & $8 \cdot 0$ & 420 & 24 & 440 & 36 \\
\hline Vitamin A-deficient & $0 \cdot 5^{* * *}$ & $0 \cdot 1$ & $0 \cdot 4 * * *$ & 0.1 & $24 * * *$ & 3 & $28^{* * *}$ & 3 \\
\hline
\end{tabular}

Mean values were significantly different from those of any of the other dietary groups $\left(t\right.$ test): ${ }^{* * *} P<0.001$. $\dagger$ For details, see p. 476.

immunized animals the antibody levels were measured using pooled sera from each group. The antibody titre of the non-immunized animals served as the background antibody level. In the immunized animals, the antibody titres were measured in duplicate. The total serum antibody levels specific to rotavirus in the immunized animals were not greatly higher than those of non-immunized animals. For the immunized groups, there was no significant difference in the antibody levels observed for vitamin A-deficient, control or pair-fed 
Table 4. Serum antibody levels specific to rotavirus of groups of mice given one of the three experimental diets for 12 weeks and an intraperitoneal injection of rotavirus at week 11

(Results are expressed as the units of anti-rotavirus activity extrapolated from the standard curve of the standard serum. For non-immunized groups results are the mean of pooled serum of five samples in each dietary group, and for immunized group mean values with their standard errors are for five samples per dietary group)

\begin{tabular}{|c|c|c|c|c|}
\hline & \multirow[b]{2}{*}{ Dietary group* } & \multirow{2}{*}{$\frac{\begin{array}{c}\text { Non-immunized } \\
\text { (units) }\end{array}}{\text { Mean }}$} & \multicolumn{2}{|c|}{$\begin{array}{l}\text { Immunized } \\
\text { (units) }\end{array}$} \\
\hline & & & Mean & SEM \\
\hline & Control & 170 & 196 & 37 \\
\hline & Pair-fed & 138 & 227 & 28 \\
\hline & Vitamin A-deficient & 159 & 230 & 46 \\
\hline
\end{tabular}

* For details, see p. 476

animals (by Wilcoxon test). Therefore, unlike oral dosing, intraperitoneal immunization with EDIM rotavirus failed to provoke a specific antibody response.

\section{DISCUSSION}

The present study was designed to investigate the relationship between vitamin A deficiency and the immune response to rotavirus presented either by oral dosing or by immunization following intraperitoneal injection.

The effect of vitamin A deficiency on antibody production has been investigated by a number of workers but most of these studies were carried out using either the intraperitoneal or the intramuscular administration route. A very few studies have investigated the consequence of vitamin A deficiency on the antibody production following oral dosing of the antigen (Sirisinha et al. 1980) and particularly oral dosing of live antigen. In the present study, following oral dosing of the live EDIM rotavirus there was a substantial increase in the antibody production in the animals of all dietary groups compared with their nondosed counterparts. Following oral dosing, there was a statistically-significant reduction in antibody production specific to rotavirus in the vitamin A-deficient mice compared with control and pair-fed animals. In contrast, following intraperitoneal immunization the antibody production was not greatly increased compared with that of the non-immunized animals and there was no statistically-significant difference in the antibody level amongst any of the dietary groups.

In the group which received oral dosing, the administration of both rotavirus and picryl chloride challenge, led to a fall in body-weight in all groups. This was correlated with a reduced intake of food in the infected animals. Body-weight did not fall following oral challenge of rotavirus alone (Ahmed et al., 1990) nor following intraperitoneal immunization. Therefore, the reduction in body-weight seen after oral challenge in the present study may be attributed to the administration of picryl chloride acting either alone or synergistically with rotavirus.

In the present study it was observed that the liver vitamin $A$ in the deficient animals was almost completely exhausted. Further, the serum vitamin $\mathrm{A}$ levels in the vitamin A-deficient animals were significantly lower than those of control and pair-fed animals, confirming that the animals were vitamin A deficient. Following oral administration of rotavirus and picryl chloride challenge the serum vitamin A levels of all the infected groups were lower than those of the non-infected groups; liver vitamin A levels remained unchanged, however. A 
possible explanation for this observation might be a limited synthesis of retinol-binding protein (RBP) by the liver. RBP behaves as a negative acute-phase reactant during infection and stress.

The present study has shown that following oral dosing with rotavirus, vitamin A deficiency reduces the level of anti-rotavirus antibody in the serum. The antibody response in the gastrointestinal tract is attributed mainly to $\operatorname{IgA}$ which is produced locally by the plasma cells within the intestinal lamina propria (Kagnoff et al. 1973). The secretory component (SC), a glycoprotein, on the basal and lateral plasma membrane of the intestinal surface epithelium cells (Brown et al. 1977), acts as a membrane receptor for immunoglobulin A (IgA) and facilitates the transportation of $\operatorname{IgA}$ into the intestinal epithelial cells. After complexing with dimeric IgA, membrane-bound IgA-SC is eventually transported to the gut lumen. There is evidence that in mammals, but not in man, a large percentage of dimeric IgA, without SC, enters the lymphatics draining the intestine and eventually the circulation (Vaerman \& Heremans, 1970). Thus, oral virus should provoke a local stimulation of $\operatorname{IgA}$ antibody in the gut leading to increased antibody secretion and increased concentration in the serum. Therefore, our findings are indicative of defective or decreased antibody production after the oral dosing of rotavirus. Sirisinha et al. (1980) immunized rats to dinitrophenol (DNP)-BCG using both the oral and intraperitoneal route at the same time. They found that vitamin A-deficient rats demonstrated an impaired secretory anti-DNP antibody response, but were only marginally affected in terms of their systemic anti-DNP response. The authors suggested that the deficiency of vitamin A affected the synthesis of SC rather than the production of secretory $\operatorname{IgA}$ itself by plasma cells, the consequence being a failure of transport of $\operatorname{IgA}$ into the intestinal lumen.

The effect of vitamin A deficiency on the systemic immune response against rotavirus by intraperitoneal injection was investigated. It was not possible to demonstrate a significant increase in rotavirus antibody levels in any of the dietary groups following intraperitoneal immunization with $30 \mu 1$ EDIM rotavirus/mouse. Smith \& Hayes (1987) have shown that the serum IgG levels of vitamin A-deficient mice were significantly lower than those of control animals following intraperitoneal immunization with haemocyanin. Further, Harmon et al. (1963) have shown that vitamin A-deficient swine had significantly reduced antibody levels against phenolized Salmonella pullorum antigen when compared with controls.

It might be argued that the lack of response in antibody production following intraperitoneal immunization was due to the use of an insufficient dose of antigen. Since the rotavirus used replicates within the gut, after oral dosing antigen replication would effectively increase the antigenic challenge. Following intraperitoneal immunization the rotavirus would not be able to replicate and, thus, the dose of immunogen might have been insufficient to provoke an antibody response.

The impaired antibody response following oral challenge could be the result of a defect in either B-cells, T-cells or both cell types. In order to investigate the T-cell function, we investigated delayed-type hypersensitivity (DTH), an accepted index of cell-mediated immunity (Roitt et al. 1985). We observed an impaired DTH response to the skin-contact antigen tri-nitrochlorobenzene (picryl chloride) in the vitamin A-deficient mice compared with control and pair-fed animals. These observations confirm that vitamin A deficiency impairs the cell-mediated immune response. The DTH response involves lymphokines released by helper T-cells among many other factors (Roitt et al. 1985). Therefore, the combination of impaired DTH and lowered humoral immunity provides evidence that vitamin $\mathrm{A}$ deficiency may lead to defective $\mathrm{T}$-cell function.

Restoring vitamin A levels in the diet 1 week before infection partially restored the capacity of vitamin A-deficient animals to mount an antibody response following rotavirus 
infection. Although the antibody levels were not significantly different from those of vitamin A-deficient animals, the overall antibody production appeared to have improved since there was no difference observed between the refed and control groups. After 2 weeks of refeeding vitamin A there was no significant improvement in the delayed hypersensitivity response.

We conclude that vitamin A deficiency may impair both the humoral and cell-mediated immunity in the adult mouse, thereby increasing susceptibility to rotavirus.

The authors thank the Commonwealth Scholarship Commission, London and Wessex Medical School Trust for their financial support during this work. They thank Dr Starkey and his colleagues, Department of Microbiology, University of Birmingham, UK for supplying the EDIM rotavirus strain.

\section{REFERENCES}

Ahmed, F., Jones, D. B. \& Jackson, A. A. (1990). The interaction of vitamin A deficiency and rotavirus infection in the mouse. British Journal of Nutrition 63, 363-373.

American Institute of Nutrition (1977). Reports of the American Institute of Nutrition Ad Hoc Committee on standards for nutritional studies. Journal of Nutrition 107, 1340-1348

Bang, F. B. \& Foard, M. A. (1971). The effect of acute vitamin A deficiency on the susceptibility of chicks to Newcastle disease and influenza viruses. Johns Hopkins Medical Journal 129, 100-109.

Bayfield, R. F. (1975). Simplified methods for the examination of liver lipids. I. Determination of vitamin A in liver using a direct solvent extraction technique. Analytical Biochemistry 64, 403-413.

Bieri, J. G., Tolliver, T. J. \& Catignani, G. L. (1979). Simultaneous determination of $\alpha$-tocopherol and retinol in plasma or red cells by high-pressure liquid chromatography. American Journal of Clinical Nutrition 32, 2143 2149

Brown, W. R., Kiyoko, I., Nakane, P. K. \& Pacini, B. (1977). Studies on translocation of immunoglobulins across intestinal epithelium. IV. Evidence for binding of $\operatorname{IgA}$ and $\operatorname{IgM}$ to secretory component in intestinal epithelium. Gastroenterology 73, 1333-1339.

Chandra, R. K. \& Au, B. (1981). Single nutrient deficiency and cell mediated immune responses. 3. Vitamin A. Nutrition Research 1, 181-185.

Davis, C. Y. \& Sell, J. L. (1983). Effect of all-trans retinol and retinoic acid nutriture on the immune system of chicks. Journal of Nutrition 113, 1914-1919.

Goldstone, L. A. (1983). Understanding Medical Statistics. London: William Heinemann Medical Books Ltd.

Harmon, B. G., Miller, E. R., Hoefer, J. A., Ullrey, D. E. \& Luecke, R. W. (1963). Relationship of specific nutrient deficiencies to antibody production in swine. 1. Vitamin A. Journal of Nutrition 79, 263-268.

Kagnoff, M. F., Serfilippi, D. \& Donaldson, M. R. (1973). In vitro kinetics of intestinal secretory IgA secretion. Journal of Immunology 110, 297-300.

Krishnan, S., Bhuyan, U. N., Talwar, G. P. \& Ramalingaswami, V. (1974). Effect of vitamin A and protein-calorie undernutrition on immune responses. Immunology 27, 383-392.

Krishnan, S., Krishnan, A. D., Mustafa, A. S., Talwar, G. P. \& Ramalingaswami, V. (1976). Effect of vitamin A and undernutrition on the susceptibility of rodents to a malarial parasite Plasmodium berghei. Journal of Nutrition 106, 784-791

Ludovici, P. P. \& Axelrod, A. E. (1951). Circulating antibodies in vitamin-deficiency states. Pteroylglutamic acid, niacin-tryptophan, vitamin $\mathrm{B}_{12}, \mathrm{~A}$ and $\mathrm{D}$ deficiencies. Proceedings of the Society for Experimental Biology and Medicine 77, 526-530.

Nauss, K. M., Anderson, C. A., Conner, M. W. \& Newberne, P. M. (1985). Ocular infection with Herpes Simplex Virus (HSV-1) in vitamin A-deficient and control rats. Journal of Nutrition 115, 1300 1315.

Panda, B. \& Combs, G. F. (1963). Impaired antibody production in chicks fed diets low in vitamin A, pantothenic acid or riboflavin. Proceedings of the Society for Experimental Biology and Medicine 113, 530534.

Pirie, A. (1983). Vitamin A deficiency and child blindness in the developing world. Proceedings of the Nutrition Society 42, 53-64.

Pruzansky, J. \& Axelrod, A. E. (1955). Antibody production to diphtheria toxoid in vitamin A deficiency states. Proceedings of the Society for Experimental Biology and Medicine 89, 323-325.

Rocls, O. A. (1970). Vitamin A physiology. Journal of the American Medical Association 214, 1097-1102.

Roitt, I. M., Brostoff, J. \& Male, D. K. (1985). Immunology. London: Gower Medical Publishing Ltd.

Sirisinha, S., Darip, M. D., Moongkarndi, P., Ongsakul, M. \& Lamb, A. J. (1980). Impaired local immune response in vitamin A-deficient rats. Clinical and Experimental Immunology 40, 127-135.

Smith, S. M. \& Hayes, C. E. (1987). Contrasting impairments in IgM and IgG responses of vitamin A-deficient mice. Proceedings of the National Academy of Sciences, USA 84, 5878-5882. 
Starkcy, W. G., Collins, J., Wallis, T. S., Clarke, G. J., Spencer, A. J., Haddon, S. J., Osborne, M. P., Candy, D. C. A. \& Stephen, J. (1986). Kinetics, tissue specificity and pathological changes in murine rotavirus infection of mice. Journal of General Virology 67, 2625-2634.

Vearman, J. P. \& Heremans, J. F. (1970). Origin and molecular size of immunoglobulin A in the mesenteric lymph node of the dog. Immunology 18, 27-38. 